\title{
Isolation and characterization of 11 novel microsatellite loci in a West African leaf-nosed bat, Hipposideros aff. ruber
}

Heather J Baldwin ${ }^{1,2^{*}}$, Peter Vallo ${ }^{1,3}$, Michael G Gardner ${ }^{4,5}$, Christian Drosten ${ }^{6}$, Marco Tschapka ${ }^{1,7}$ and Adam J Stow ${ }^{2}$

\begin{abstract}
Background: Noack's leaf-nosed bat, Hipposideros ruber, is a cryptic species within the Hipposideros caffer species complex. Despite a widespread distribution in Africa and being host to potentially zoonotic viruses, the genetic structure and ecology of $\mathrm{H}$. ruber is poorly known. Here we describe the development of 11 novel polymorphic microsatellite loci to facilitate the investigation of genetic structure.
\end{abstract}

Findings: We selected 20 microsatellite sequences identified from high throughput sequence reads and PCR amplified these for 38 individuals, yielding 11 consistently amplifying and scorable loci. The number of alleles per locus ranged from two to 12 , and observed heterozygosities from 0.00 to 0.865 . No evidence of linkage disequilibrium was observed, and nine of the markers showed no departure from Hardy-Weinberg equilibrium. We demonstrate successful amplification in two closely related species and two divergent lineages of the $H$. caffer species complex.

Conclusions: These new markers will provide a valuable tool to investigate genetic structure in the poorly understood Hipposideros caffer species complex.

Keywords: Hipposideros ruber, Hipposideros caffer, Microsatellites, Population genetics, Microchiroptera, Hipposideridae, Bat

\section{Findings}

Noack's leaf-nosed bat Hipposideros ruber (Noack, 1893) is one of two recognised cryptic species within the Hipposideros caffer (Sundevall, 1846) species complex. These bats are widespread throughout sub-Saharan Africa and among the most abundant mammals on the continent $[1,2]$. Mitochondrial evidence has shown the existence of several deeply divergent lineages within the $H$. caffer complex, which most likely constitute more than the two species [3]. Recently, they have been discovered to host viruses with zoonotic potential [4], emphasizing the need for knowledge about their ecology in order to gain insight into zoonotic processes and risk factors for public health. Microsatellites provide a powerful tool to

\footnotetext{
* Correspondence: heather.baldwin@uni-ulm.de

'Institute of Experimental Ecology, University of Ulm, Albert-Einstein-Allee 11, 89069 Ulm, Germany

${ }^{2}$ Department of Biological Sciences, Macquarie University, Sydney, New

South Wales 2109, Australia

Full list of author information is available at the end of the article
}

investigate the poorly known ecology and life history of these bats, including genetic structure, social arrangements and mating systems. Assessment of nuclear gene flow through microsatellite analysis may thus help to shed light also on the taxonomy of this species complex.

We isolated and characterized 11 microsatellite loci from a single, exclusively West African mitochondrial lineage of Hipposideros ruber, determined by sequencing of the cytochrome $b$ gene [lineage $\mathrm{D} ; 3$ ]. This lineage is henceforth called $H$. aff. ruber due to its distant evolutionary relationship to $H$. ruber s. str. from East Africa, and may represent a distinct species [3]. Hipposideros aff. ruber has been previously identified in central Ghana [5] and seems to be the most abundant of the three main lineages of the $H$. caffer complex in this region (unpublished data). The markers described herein represent, to our knowledge, the first suite of microsatellites for an African hipposiderid bat.

DNA was extracted from wing tissue from eight individuals sampled from the Brong Ahafo and Volta regions 
in central Ghana. DNA was extracted using an innuPREP DNA mini kit (Analytik Jena, Jena, Germany). Five micrograms of pooled DNA from eight individuals was sent to AGRF (www.agrf.com.au), where high throughput sequencing was performed on a Roche GS FLX 454 sequencing machine as described elsewhere [6-8]. QDD 1.3 [9] was used to screen for di- to hexanucleotide repeat motifs with a minimum of eight repeats. From the 1689 microsatellites identified, a total of 32 primer pairs flanking tetranucleotide repeats with 11-15 repeat motifs were designed using PRIMER3 [10]. Twenty primer pairs for which the annealing temperatures were most similar for each primer were selected for initial amplification trials. Amplification products from these primer pairs were visualised by electrophoresis on an agarose gel, from which 13 pairs with strong, stutter-free amplification bands were selected for optimisation. Forward primers for these 13 loci were directly labelled with a fluorochrome at the $5^{\prime}$ end. Twelve of these loci were successfully amplified by polymerase chain reaction (PCR), with one discarded due to the excessive amplification of nonspecific product. PCR conditions for these 12 loci were optimized and genotyping was performed on 38 individuals (16 females, 22 males) sampled in Brong Ahafo and Volta Regions.

PCRs were performed using 10-50 ng of template DNA and reagent concentrations as follows: $200 \mu \mathrm{M}$ each dNTP, one unit reaction buffer, between 2.0 and $2.5 \mathrm{mM}$ $\mathrm{MgCl}_{2}$, equal concentrations of forward and reverse primer $(0.25-1.0 \mu \mathrm{M})$ and one unit Taq polymerase (see Table 1). PCR amplification consisted of an initial denaturation at $94^{\circ} \mathrm{C}$ for $3 \mathrm{~min}$ followed by six touchdown cycles of $94^{\circ} \mathrm{C}$ denaturation for $30 \mathrm{~s}$, annealing for $30 \mathrm{~s}$ with temperatures decreased by $2^{\circ} \mathrm{C}$ per cycle $\left(55-47^{\circ} \mathrm{C}, 60-50^{\circ} \mathrm{C}\right.$, or $65-55^{\circ} \mathrm{C}$; Table 1$)$, and polymerase extension step at $72^{\circ} \mathrm{C}$ for $45 \mathrm{~s}$. An additional 35 cycles were conducted, of denaturation $\left(94^{\circ} \mathrm{C}, 30 \mathrm{~s}\right)$, primer annealing (final touchdown temperature, $45 \mathrm{~s}$ ), and polymerase extension $\left(72^{\circ} \mathrm{C}, 45 \mathrm{~s}\right)$, followed by a final extension $\left(72^{\circ} \mathrm{C}, 10 \mathrm{~min}\right)$. PCR products were

Table 1 Characteristics and thermocycling conditions for 11 polymorphic microsatellites in the African leaf-nosed bat Hipposideros aff. ruber

\begin{tabular}{|c|c|c|c|c|c|c|c|c|c|c|c|c|}
\hline Locus & Accession \# & $\begin{array}{l}\text { Repeat } \\
\text { motif }\end{array}$ & Primer sequences $\left(5^{\prime}-3^{\prime}\right)$ & $\mathrm{MgCl}_{2} / P_{\mathrm{FR}}$ & $\operatorname{Ta}\left({ }^{\circ} \mathrm{C}\right)$ & Size (bp) & $\mathrm{N}$ & $\mathrm{N}_{\mathrm{A}}$ & $\mathrm{H}_{\mathrm{O}}$ & $\mathrm{H}_{\mathrm{E}}$ & HWE & $\mathrm{P}_{\mathrm{NULL}}$ \\
\hline \multirow{2}{*}{ Hr1 } & \multirow{2}{*}{ KM370156 } & \multirow{2}{*}{$(\text { GATA })_{13}$} & F:TGGCAAGGTTAACACGAACC & \multirow{2}{*}{$2.0 \mathrm{mM} / 0.5 \mu \mathrm{M}$} & \multirow{2}{*}{$60-50$} & \multirow{2}{*}{$238-258$} & \multirow{2}{*}{38} & \multirow{2}{*}{6} & \multirow{2}{*}{0.74} & \multirow{2}{*}{0.79} & \multirow{2}{*}{ ns } & \multirow{2}{*}{0.028} \\
\hline & & & R:TCTCCCTCCCGCTCTTATCT & & & & & & & & & \\
\hline \multirow{2}{*}{$\mathrm{Hr} 2$} & \multirow{2}{*}{ KM370157 } & \multirow{2}{*}{$(\mathrm{TCTT})_{15}$} & F:GAAGCACTGCTGGAAAGGTT & \multirow{2}{*}{$2.0 \mathrm{mM} / 0.25 \mu \mathrm{M}$} & \multirow{2}{*}{$60-50$} & \multirow{2}{*}{ 311-339 } & \multirow{2}{*}{34} & \multirow{2}{*}{8} & \multirow{2}{*}{0.77} & \multirow{2}{*}{0.76} & \multirow{2}{*}{ ns } & \multirow{2}{*}{-0.009} \\
\hline & & & R:GTTGAACTGGGTGGCCTITA & & & & & & & & & \\
\hline \multirow{2}{*}{ Hr5 } & \multirow{2}{*}{ KM370160 } & \multirow{2}{*}{$(\mathrm{GAAG})_{14}$} & F:TGGGTGTTTCAGTITCATGC & \multirow{2}{*}{$2.0 \mathrm{mM} / 0.5 \mu \mathrm{M}$} & \multirow{2}{*}{$65-55$} & \multirow{2}{*}{ 186-234 } & \multirow{2}{*}{34} & 0 & רס & רס & & \\
\hline & & & R:TGGTCTATTTGTTCCTTCCGTA & & & & & $y$ & 0.02 & 0.02 & 115 & \\
\hline & & & F:GGGTTTCTTCAAATGTGTTITC & & & & & & & & & \\
\hline Hr6 & KMз/0161 & $(\mathrm{ICII})_{13}$ & R:GCCTCCAAGACAAACAGAGG & $15 \mu \mathrm{M}$ & $55-47$ & $204-240$ & 37 & 8 & 0.70 & 0.73 & ns & 0.0 \\
\hline 7 & 1501370167 & $\Delta T+$ & F:AGCCAATGACAAGACTGCCTA & 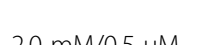 & 55 & 14.177 & $32+3>2$ & 8 & 7 & 68 & **** $>>>>$ & \\
\hline Hry & KIVIS/OIOL & $(A \mid I I) 11$ & R:CCAGTGAAGCAACGTCCTCT & v & -53 & 2 & 33 & 8 & 0.42 & 0.08 & & $0.1 / 3$ \\
\hline & & & F:CTCAGCCCAAAGTCAAGGAG & & & & & & & & & \\
\hline r8 & KIVI/0163 & 12 & R:TGGCTATACGAATACAAAGATTAGACA & $n / M / O .5 \mu M$ & $60-50$ & $21-24 \mid$ & 36 & 6 & $.1 / 2$ & 0.68 & ns & \\
\hline Hr9 & KMM370164 & & F:TGCTATCTTCCATGAGGTCAGA & M & $60-50$ & $218-231$ & 38 & 5 & 163 & 73 & ac & \\
\hline III & 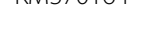 & (1 & R:TCTCTGTTGCTGAAGGAAAACTT & 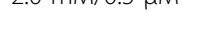 & & 210 & & & & & & \\
\hline Hr10 & KM370165 & (TTAD & F:TCCACTGGAGTAAGAGATGTGTG & $20 \mathrm{mM} / 10 u$ & $65-55$ & $258-282$ & 38 & 7 & 079 & 074 & DS & $-0,040$ \\
\hline III & S & (17)1111 & R:GCACTGCAACAGTGAAAAGC & 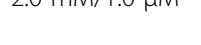 & הכל- & $230=202$ & 50 & 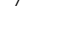 & 0.13 & 0.74 & $\pi 15$ & \\
\hline Hr11 & $K M$ & & F:CTCTTGCAATGAAGGCAATG & 1 & $65-55$ & 1 & 37 & 12 & 87 & 96 & & \\
\hline . & 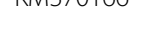 & 114 & R:CTGCCATGAGCTACCATGAG & 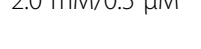 & $03-53$ & 100-154 & $3 \gamma$ & 12 & 0.01 & 0.00 & 115 & 18 \\
\hline Hr12 & KMM370167 & 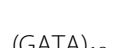 & F:TTGGTTTCAGATCTTCTGGTG & $m M a / 0$ - 5 Ml & $2-5$ & 3 & 38 & 1 & 12 & 60 & ** & \\
\hline ח112 & 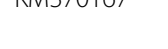 & $(U A T A) 12$ & R:GAGTCTTCTGCCTGCTGGAC & 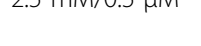 & $00=50$ & $211-293$ & 50 & 4 & 0.42 & 0.00 & & 0.140 \\
\hline Hr13 & KMM370168 & $f$ & F:CCGAAGCCAATCTGGTTTTA & $\mathrm{ms} / 10$ & 55 & 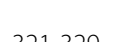 & 31 & $?$ & 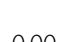 & $0 \cap 06$ & $\operatorname{ng}$ & 0157 \\
\hline III & 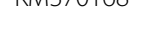 & $(I I I C) 13$ & R:GGGTCCTGCAGAAACACACT & 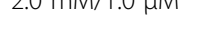 & $03-53$ & $3<1-5<9$ & 34 & 2 & 0.00 & 0.00 & ns & $0.15 \%$ \\
\hline
\end{tabular}

$P_{\mathrm{FR}}$ forward and reverse primer concentration, $\mathrm{Ta}$ annealing temperatures of touchdown cycles (see Methods), $\mathrm{N}$ number of individuals, $\mathrm{N}_{\mathrm{A}}$ number of alleles, $\mathrm{H}_{\mathrm{O}}$ observed heterozygosity, $\mathrm{H}_{\mathrm{E}}$ expected heterozygosity, HWE probability of deviation from Hardy-Weinberg equilibrium, $\mathrm{P}_{\mathrm{NULL}}$ null allele frequency estimate (van Oosterhout), ns not significant., ${ }^{* *} \mathrm{p}<0.01$, ${ }^{* * *} \mathrm{p}<0.001$. 
Table 2 Cross-amplification success in other Hipposideros species or lineages

\begin{tabular}{|c|c|c|c|c|c|c|c|c|c|c|c|}
\hline Taxon & Hr1 & $\mathrm{Hr} 2$ & Hr5 & Hr6 & Hr7 & Hr8 & $\mathrm{Hr} 9$ & Hr10 & Hr11 & $\mathrm{Hr} 12$ & Hr13 \\
\hline H. abae & + & + & + & + & + & + & + & + & + & + & + \\
\hline H. tephrus & + & + & + & + & + & + & + & + & - & + & + \\
\hline H. ruber (lin. B $)^{\S}$ & + & + & + & + & + & + & + & + & + & + & + \\
\hline H. ruber $(\operatorname{lin} . \mathrm{C})^{\S}$ & + & + & + & + & + & + & + & + & + & + & + \\
\hline
\end{tabular}

+successful amplification with 1-2 bands visualised of expected size, - no PCR product observed.

§sensu Vallo et al. 2008. lin. = lineage.

electrophoresed using an ABI3130 Genetic Analyzer (Applied Biosystems, Foster City, CA, USA). Allele sizes were determined via manual inspection using the software PEAK SCANNER 1.0 (Applied Biosystems), followed by automated binning performed using TANDEM 1.09 [11]. We reanalyzed $20 \%$ of individuals to evaluate data integrity. One locus $(\mathrm{Hr} 3)$ was discarded due to high rounding error in the TANDEM analysis, indicating poor marker quality. MICRO-CHECKER 2.2.3 was used to assess the probability of scoring errors, allelic dropout and the presence of null alleles [12]. No scoring errors or allelic dropout were detected, although there were potentially null alleles at loci Hr7 and Hr12. Locus Hr13 may also suffer from null alleles, though low allelic variability (one common and one rare allele) did not allow this to be confirmed (Table 1).

The program CERVUS was used to calculate number of alleles, observed $\left(H_{\mathrm{o}}\right)$ and expected $\left(H_{\mathrm{e}}\right)$ heterozygosities, and probabilities of identity [13]. All 11 loci were determined to be polymorphic, with a range of 2-12 alleles per locus (Table 1). Tests for pairwise linkage disequilibrium and deviations from Hardy-Weinberg equilibrium with Bonferroni corrections were calculated using FSTAT 2.9.3 [14]. Two loci (Hr7, Hr12) deviated significantly from the Hardy-Weinberg equilibrium with a homozygote excess (Table 1). No linkage disequilibrium was detected between any loci. The probability of identity for the 11 loci was low at $1.6 \mathrm{E}^{-10}$ overall, and $8.7 \mathrm{E}^{-10}$ and $3.1 \mathrm{E}^{-9}$ for the Brong Ahafo and Volta localities, respectively. Probability of sibling identity was $1.4 \mathrm{E}^{-4}, 2.2 \mathrm{E}^{-4}$ and $2.8 \mathrm{E}^{-4}$ for overall, Brong Ahafo and Volta, respectively.

In order to explore utility in closely related taxa, we tested whether these loci could be amplified across four related taxa in the genus Hipposideros using the PCR conditions specified above (Table 2). All but one locus successfully amplified PCR product across the tested taxa.

These microsatellite loci provide useful resources for the study of population genetic structure of bats in the Hipposideros caffer complex, and likely also related species in this genus. These findings will help to address questions regarding connectivity, social behaviour, and zoonotic disease ecology in African leaf-nosed bats.

\section{Ethics statement}

All animals were handled in accordance with Ghanaian legislation. Bat capture and sampling were authorized by permit from the Wildlife Division of the Ministry of Lands, Forestry and Mines in Ghana, and approved by the Macquarie University Ethics Committee. Exports were conducted under a state agreement between the Republic of Ghana and the Federal Republic of Germany, and to Australia with permission from the Department of Agriculture, Fisheries and Forestry.

\section{Availability of the supporting data}

The microsatellite sequences are available through the National Centre for Biotechnology Information (http:// www.ncbi.nlm.nih.gov); GenBank accession numbers KM370156 - KM370168.

\section{Competing interests}

The authors declare that they have no competing interests.

\section{Authors' contributions}

AS was responsible for the design of this study, supervision of the work and contributed to the interpretation of results. HB performed field sampling, data analysis and marker validation, and HB and PV drafted the manuscript. MG contributed to analysis of sequences. CD and MT coordinated field sampling and were responsible for the implementation of the study. All authors read and approved the final manuscript.

\section{Acknowledgements}

This work was supported by the German Research Foundation and funds from Macquarie, Ulm and Bonn Universities. We would like to thank S. Oppong for valuable assistance with permits and logistics. We thank all those involved in fieldwork, in particular E. E. Nkrumah, P. Anti, and E. K. Badu. We thank the communities of Buoyem and Likpe Todome for their hospitality and for providing access to the sites.

\section{Author details}

${ }^{1}$ Institute of Experimental Ecology, University of UIm, Albert-Einstein-Allee 11, 89069 Ulm, Germany. ${ }^{2}$ Department of Biological Sciences, Macquarie University, Sydney, New South Wales 2109, Australia. ${ }^{3}$ Institute of Vertebrate Biology, v. v. i., Academy of Sciences of the Czech Republic, Květná 8, 60365 Brno, Czech Republic. ${ }^{4}$ School of Biological Sciences, Flinders University, Adelaide, South Australia 5001, Australia. ${ }^{5}$ Evolutionary Biology Unit, South Australian Museum, North Terrace, Adelaide, South Australia 5000, Australia. ${ }^{6}$ Institute of Virology, University of Bonn Medical Center, Sigmund-Freud-Str 25, 53105 Bonn, Germany. ${ }^{7}$ Smithsonian Tropical Research Institute, PO Box 0843-03092, Balboa, Panama.

Received: 8 July 2014 Accepted: 28 August 2014 Published: 4 September 2014 


\section{References}

1. Brosset $A$ : Chiroptères d'altitude du mont nimba (guinée). description d'une espèce nouvelle, hipposideros lamottei. Mammalia 1984, 48:545-556.

2. Wright G: Hipposideros caffer (chiroptera: hipposideridae). Mamm Species 2009, 845:1-9.

3. Vallo P, Guillén-Servent A, Benda P, Pires D, Koubek P: Variation of mitochondrial DNA in the hipposideros caffer complex (chiroptera: hipposideridae) and its taxonomic implications. Acta Chiropterologica 2008, 10:193-206.

4. Pfefferle S, Oppong S, Drexler J, Gloza-Rausch F, Ipsen A, Seebens A, Müller M, Annan A, Vallo P, Adu-Sarkodie Y, Kruppa T, Drosten C: Distant relatives of severe acute respiratory syndrome coronavirus and close relatives of human coronavirus 229E in bats, Ghana. Emerg Infect Dis 2009, 15:1377-1384

5. Vallo P, Benda P, Martínková N, Kaňuch P, Kalko EK, Červený J, Koubek P: Morphologically uniform bats hipposideros aff. ruber (hipposideridae) exhibit high mitochondrial genetic diversity in southeastern senegal. Acta Chiropterologica 2011, 13:79-88.

6. Margulies M, Egholm M, Altman W, Attiya S, Bader J, Bemben L, Berka J, Braverman M, Chen Y, Chen Z: Genome sequencing in microfabricated high-density picolitre reactors. Nature 2005, 437:376-380.

7. Boomer J, Stow A: Rapid isolation of the first set of polymorphic microsatellite loci from the Australian gummy shark, mustelus antarcticus and their utility across divergent shark taxa. Conserv Gen Res 2010, 2:393-395.

8. Gardner MG, Fitch AJ, Bertozzi T, Lowe AJ: Rise of the machines recommendations for ecologists when using next generation sequencing for microsatellite development. Mol Ecol Res 2011 11:1093-1101.

9. Meglécz E, Costedoat C, Dubut V, Gilles A, Malausa T, Pech N, Martin J-F: QDD: a user-friendly program to select microsatellite markers and design primers from large sequencing projects. Bioinformatics 2010, 26:403-404.

10. Rozen S, Skaletsky H: Primer3 on the WWW for general users and for biologist programmers. Methods Mol Biol 2000, 132:365-386.

11. Matschiner M, Salzburger W: TANDEM: integrating automated allele binning into genetics and genomics workflows. Bioinformatics 2009, 25:1982-1983.

12. van Oosterhout C, Hutchinson W, Wills D, Shipley P: MICRO-CHECKER: software for identifying and correcting genotyping errors in microsatellite data. Mol Ecol Notes 2004, 4:535-538.

13. Kalinowski ST, Taper ML, Marshall TC: Revising how the computer program CERVUS accommodates genotyping error increases success in paternity assignment. Mol Ecol 2007, 16:1099-1106.

14. Goudet J: FSTAT (version 1.2): a computer program to calculate F-statistics. $J$ Hered 1995, 86:485-486.

\section{doi:10.1186/1756-0500-7-607}

Cite this article as: Baldwin et al:: Isolation and characterization of 11 novel microsatellite loci in a West African leaf-nosed bat, Hipposideros aff. ruber. BMC Research Notes 2014 7:607.

\section{Submit your next manuscript to BioMed Central and take full advantage of:}

- Convenient online submission

- Thorough peer review

- No space constraints or color figure charges

- Immediate publication on acceptance

- Inclusion in PubMed, CAS, Scopus and Google Scholar

- Research which is freely available for redistribution 